\title{
Human System Interface Concerns in Support System Design*
}

\author{
GUNNAR JOHANNSEN, $†$ JOHN E. RIJNSDORP $\ddagger$ and ANDREW P. SAGE§ \\ Newly emerging technologies require that attention to physiological controlling tasks, \\ traditional in man-machine systems studies, be augmented with concerns for cognitive \\ interfaces and interactions between human problem solving and knowledge based support \\ systems for systems control.
}

Key Words-Knowledge based systems; decision support systems; man-machine systems; expert systems; human supervisory control; human computer interaction.

\begin{abstract}
Current research needs and future prospects in the area of support to man-machine system analysis, design, and evaluation are described. We are especially concerned with system design requirements to enable efficient and effective human system interaction. Prospects for enhanced support to the human operator, in problem solving cognitive tasks that involve planning and design as well as physiological tasks that involve controlling, through use of knowledge based systems and decision support systems, are discussed.
\end{abstract}

\section{INTRODUCTION}

ONE PURPOSE of this paper is to discuss knowledge based system design concerns relative to man-machine problem solving tasks; such as fault detection, diagnosis and correction. These are very important for large-scale systems control at this time. Advances in technology involving computers, automation, robotics, and many other recent innovations, together with the desire to improve productivity and the human condition, render physiological skills that involve strength and motor abilities relatively less important than they have been. They significantly increase the importance of cognitive and intellectual skills. The need for humans to monitor and maintain the conditions necessary for satisfactory operation of systems, and to cope with the poorly structured and imprecise knowledge that must be brought to bear on

\footnotetext{
* Received 23 August 1983. The original version of this paper was presented at the IFAC/IFIP/IFORS/IEA Conferece on Analysis, Design, and Evaluation of Man-Machine Systems which was held in Baden-Baden, F.R. Germany during September 1982. The published proceedings of this IFAC meeting may be ordered from Pergamon Press Ltd, Headington Hill Hall, Oxford OX3 OBW, U.K. This paper was recommended for publication in revised form by editor A. Sage.

† Laboratory for Man-Machine Systems, University of Kassel (GhK), D-3500 Kassel, F.R. Germany.

$\ddagger$ Department of Chemical Engineering, Twente University of Technology, Enschede, The Netherlands.

$\S$ Department of Systems Engineering, University of Virginia, Charlottesville, VA 22901, U.S.A.
}

unforeseen occurrences which inevitably occur in modern integrated manufacturing systems, and many other contemporary application areas, is greater than ever. Ultimately these primarily cognitive efforts, which involve a great variety of human problem solving activities, are translated into physical control signals. As a consequence of this, there are a number of human interface issues that naturally occur between the human and the machines over which they supervise.

A number of advances in electronic technology provide computer and communication systems that enable a significant increase in the amount of data that is available for judgment and decision making tasks at the problem solving level. However, even the highest quality data will generally be associated with considerable uncertainty and imprecision. Computer and communications technology can assist in human problem solving tasks by enhancing the quality of the data that is available for decision making. When this form of assistance to human problem solving tasks is provided such that reports to various requests for information are supplied, we have a classical management information system (MIS). An enhancement of a classical MIS system will enable the computer, through the incorporation of various modeling and forecasting algorithms, to respond to 'what if' type questions with 'if then' type responses. Today, the need for decision support is considerably greater than this. The great complexity of tasks make it desirable for support systems to be able to respond to 'what is the best alternative?' type questions with recommendations that are based on the value system of the problem solver and available knowledge. A system which assists in this function is called a knowledge based system by the artificial intelligence community (Barr, Cohen and Feigenbaum, 1981 and 1982; Duda and Shortliffe, 
1983; Nilsson, 1980; Winston, 1977) or a decision support system or executive support system by the management science and decision analysis community (Bennett, 1983; Keen, 1981; Sprague and Carlson, 1982). Through use of knowledge based or decision support systems we create the need for another human-system interface, one between the human and the computer, and the need for proper system design to insure appropriate interaction between the human and the computer (Card, Moran and Newell, 1983).

We consider interactions between humans and systems at each of these levels in this paper. We will first examine a simple definition for, and purpose of, a man-machine system. This leads to a discussion of the implications of new task requirements for the human, and needs for human assistance that can potentially be provided by computer support. This leads to a discussion of future prospects for developments in the design of systems for human interactions. We imbed this discussion into a brief historical survey of concerns relative to man-machine systems that allows for a perspective as well as prospectus of developments in this area of systems control.

\section{DEFINITION AND PURPOSE OF MAN-MACHINE SYSTEMS}

A man-machine system may be defined as a functional synthesis between a biological/psychological social system (the human or a group of people) and a technological system (the machine). Man-machine systems are predominantly characterized by the interaction and functional interdependence between these two elements. All kinds of technological systems, regardless of their degree of complexity, may be part of a man-machine system: industrial plants, vehicles, manipulators, prostheses, computers or management information systems. A man-machine system may, of course, be a subsystem that is incorporated within another system. We may, for example, incorporate a decision support system as part of a larger process control or computer-aided design system which also involves human interaction. This use of the term 'man-machine system' corresponds, therefore, to a specific way of looking at technological systems integrating engineering and the behavioral sciences, in particular psychology. The understanding of people--system relationships is a central goal of the human factors (Kantowitz and Sorkin, 1983) component of psychology, sometimes known as 'engineering psychology'.

Task categories such as controlling and problem solving describe typical human activities in man-machine systems. We are particularly concerned here with the design of systems to assist in human interaction with the cognitive tasks involved in problem solving and the physiological tasks involved in controlling complex systems, and the interfaces between humans and systems that are an integral part of this.

The overall purpose of any man-machine system is to provide a certain function, product, or service with reasonable costs under constraint conditions and disturbances. That involves and influences the human, the machine, or both. Figure 1 presents a simple conceptualization of man-machine systems. The primary 'inputs' to a man-machine system are a set of objectives that are typically translated into a set of expected values of performance, costs, reliability, and safety. Also, the design must be such that an acceptable level of workload and job satisfaction is maintained. It is on the basis of these that the human is able to:

1. Identify task requirements, such as to enable determination of the issues to be examined further and the issues to be not considered.

2. Identify a set of hypotheses or alternative courses of actions which may resolve the identified issues to be resolved.

3. Identify the probable impacts of the alternative courses of action.

4. Interpret these impacts in terms of the objectives or 'inputs' to the task.

5. Select an alternative for implementation and implement the resulting control.

6. Monitor performance such as to enable determination of how well the human and the system are performing.

Many researchers have described activities of this sort in a number of frameworks that include behavioral psychology, organizational management, systems engineering, and management science (Axelrod, 1972; Newell and Simon, 1972; Norman, 1981; Sage, 1977, 1981, 1982; Simon, 1978, 1983; Ungson and Braunstein, 1982).

While traditional man-machine systems analysis, like traditional ergonomics, was focused on skill based behavior and physiological concerns, new development emphasize the integration of these with formal knowledge based and heuristic rule based cognitive activities. This has been motivated

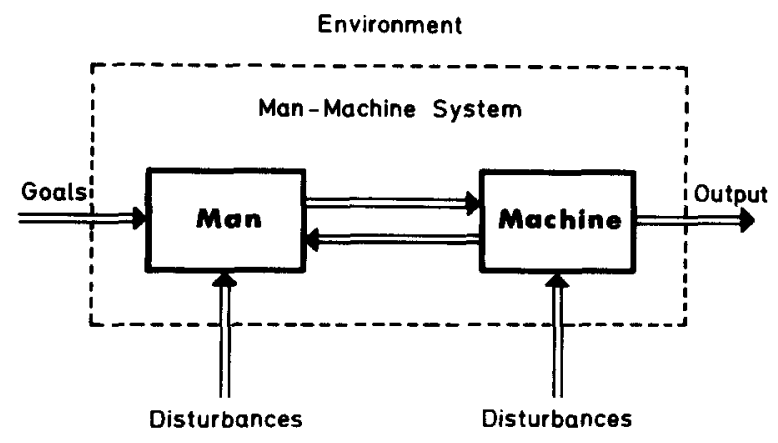

FIG. 1. Human-machine interactions. 
by the great deal of evidence that humans do not react to task requirements in a way capable of being easily stereotyped, but rather in a fashion that is very much a function of the task, the requirements perceived for the task, the environment into which the task is imbedded, and the experiential familiarity of the human with the task, the task requirements, and the environment into which these are.imbedded (Dreyfus, 1982; Dreyfus and Dreyfus, 1980; Newell and Simon, 1972; Rasmussen, 1983; Rijnsdorp, Pikaar and Lenior, 1983; Simon, 1978, 1983). Thus the focus of attention in systems design is recognized to contain major human system interaction concerns, and has shifted to systems engineering in a broad sense, particularly to the information science components of systems engineering. Questions of concern to a successful interaction between human and machine include:

What kind of information is needed?

How should this information be acquired?

How should the information be organized and structured?

How should the information be analyzed?

How should information be processed before being displayed?

How should information based judgments be formulated?

How should the information be transmitted in decentralized situations?

Any and all of these questions can arise in different application areas. These questions relate to the control of technological systems. They concern the degree of automation with respect to flexible task allocation, and they also concern the design of computer-generated displays with preprocessing capabilities. Further, they relate to all kinds of human-computer interaction concerns, as well as management tasks at different organizational levels: strategic, tactical, and operational. For example, computer-aiding prospects invade more and more areas of systems design, operation, maintenance, and management. The importance of the shifting from hardware and environmental aspects to software considerations is now captured by the new term 'software ergonomics', whereas consideration of systems engineering that involve human interaction is expressed by the term 'systems ergonomics'.

Efficiency and effectiveness criteria are vital concerns in the design of man-machine systems. Some of the goals that are the 'input' to the system are in conflict with one another. These conflicts have to be resolved in the most favorable manner by the designers of a particular man-machine system. Any deficiencies that degrade performance of the human user of the system may reduce job satisfaction and safety and, as a byproduct, effectiveness and efficiency of the overall process. Thus, contemporary and future developments in decision support and knowledge based systems become very important 'components' of the design process as it is through use of adjuvants such as these that humans are able to cope with the many competing concerns inherent in modern design efforts.

Another important feature of man-machine systems is the desire of researchers to model the human operators by applying techniques normally used for studying physical systems, and by techniques normally used to study cognitive activities. This has moved us much closer to a common 'language' for analysis and design of the whole man-machine system. This 'language' includes control theory, queueing theory, fuzzy set theory, artificial intelligence, decision analysis, and a major input of knowledge from the cognitive sciences. Future contributions to system design for human interaction can be expected to make use of knowledge from many of these diverse areas (Abelson, 1973; Anderson, 1983; Axelrod, 1976; Bobrow and Collins, 1975; Carbonell, 1981, 1983; Davis, 1979; Earnst and Banerji, 1983; Freedy and Johnson, 1982; Gupta and Sanchez, 1982a, b; Rouse, 1980; Sage and White, 1984; Schefe, 1980; Schneider and Shiffrin, 1977; Shiffrin and Schneider, 1977; Stefik and co-workers, 1982). Actual system design for human interaction will also include person oriented approaches in the field of job design and organizational science and user participation in the design process itself (Bailey, 1983; Ben-Bassat and Freedy, 1982; Burns and Minch, 1983; Moran, 1981; Moray, 1979; Mumford and Henshall, 1979).

\section{HUMAN TASK CATEGORIES}

All tasks of human personnel in man-machine systems can be condensed into two primary categories that are of principal interest here: (a) controlling (or physiological); and (b) problem solving (or cognitive). In addition, there exists a monitoring or feedback portion of the effort that enables learning. Associated with the rendering of a single judgment and the associated control implementation, the human monitors the result of the effect of these activities. The effect of present and past monitoring is to provide an experimental base for present problem conceptualization. In our categorization of the previous section, activities 1 through 4 may be categorized as problem (finding and) solving, activity 5 involves implementation or controlling, and activity 6 involves monitoring and feedback in which responses to the question 'how good is the process performance?' enables improvement and learning through iteration.

These two human task categories are fairly general. Figure 2 shows an attempt to integrate 


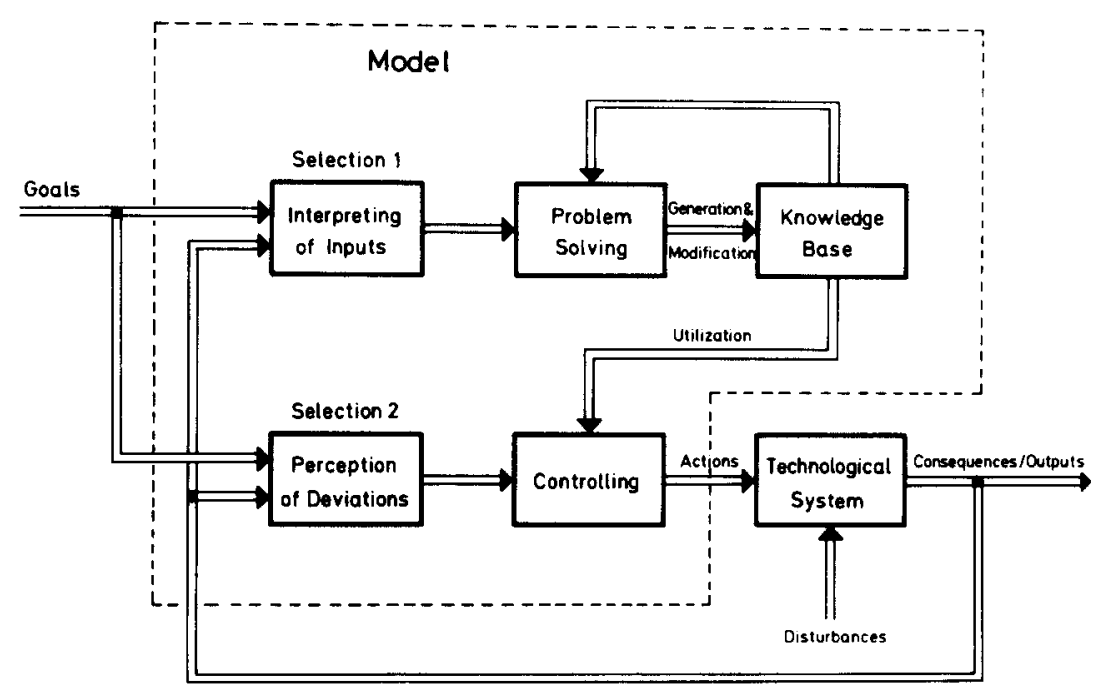

Fig. 2. Problem solving and controlling as two principal activities in knowledge based support.

them into a schematic block diagram. Controlling shall here be understood in a much broader sense than in control theory. It comprises controlling in the narrower sense, including open-loop vs closeloop and continuous vs intermittent controlling, as well as discrete tasks such as reaching, switching and typing. It is only through controlling that outputs of the man-machine system can be produced as shown in Fig. 2.

Although human functions on a cognitive level can and do play a role in control implementation, their major importance occurs in problem solving activities. Tasks such as fault detection, fault diagnosis, fault compensation or managing, and planning are particularly important in 'problem solving'. Fault detection concerns the identification of a potential difficulty concerning the operation of a system. Fault diagnosis is concerned with identification of a set of hypotheses concerning the likely cause of a system malfunction, and the evaluation and selection of a most litrely cause. It is primarily a cognitive activity. Fault compensation or managing is concerned with solving problems in actual failure situations. This may occur through the use of rules that are based on past experience, and the updating of certain rules based on the results of their present application. It is accomplished with the objective of returning the overall system to a good operating state. Fault compensation or managing involves both cognitive and physiological activities. There have been a number of studies of fault diagnosis and management in the man-machine systems literature (Johannsen, 1981; Rasmussen and Rouse, 1981; Rouse, 1982, 1983; Rouse, Rouse and Pelligrino, 1980; Rouse and Rouse, 1983). Planning is a cognitive activity concerned with solving possible future problems in the sense of mentally generating a sequence of appropriate alternatives or rules for reaching future states under different foreseeable and unforeseeable conditions (Johannsen and Rouse, 1979, 1983; Rasmussen, 1983; Sage, 1984).

In all these problem solving tasks, the skills or rules necessary to accomplish a set of tasks are stored in the knowledge base after their generation or modification. Often they are generated through a formal reasoning based effort. A cognitive engine is used to assess the specific skill or rule or formal knowledge based approach, or combination of these, useful for a specific task. From there, they can be utilized in the lower-level processes of controlling as in Fig. 2. This categorization into a knowledge base, a cognitive engine, and an interface mechanism to enable communication between these two and the users of the system, is typical in expert system approaches (Barr, Cohen and Feigenbaum, 1981 and 1982; Sage and Lagomasino, 1983; Stefik and co-workers, 1982).

There are many other tasks in man-machine systems, such as monitoring and communicating that can be classified as subtasks, or supporting tasks, of these two primary activities of problem solving and controlling. Communicating, in a man-machine systems context, comprises two very different types of communication. The first one is the verbal communication between the members of the group jointly responsible for aspects of system operation. The second type is 'communication' between humans and the technological systems to be controlled and the environment, and between humans and various support systems used to provide cognitive assistance in problem solving and control tasks. Often this latter form of communication (Card, Moran and Newell, 1983; Moran, 1981; Shneiderman, 1980) is called human-computer dialog. There are many interface concerns between humans and computers at the cognitive problem solving level, and between humans and technological systems (which may 
include computers) at the control level. These involve cognitive representations (Abelson and Rosenberg, 1958; Abelson, 1973; Bobrow and Collins, 1975; Carbonell, 1981; Hayes-Roth, 1977), selecting and representing structures for visual presentation (Badre, 1982; Schilling, McGarity and ReVelle, 1982), message summarization and formatting (Geiselman and Samat, 1982), fault management and monitoring (Johannsen, 1981), and the identification of information requirements for problem solving (Sage, Galing and Lagomasino, 1983). Thus it includes all aspects of sensing, perceiving, analysis and interpretation of the input information as conceptually illustrated by Selections 1 and 2 in Fig. 2. In this figure, the human selects only those inputs which have been selected from a larger set of generally available information for use in a particular application. This selection is handled differently for purpose of problem solving where information inputs are acquired, analyzed, and interpreted; and for purpose of controlling where, at a much more intensive time pace, deviations are perceived and input to the human problem solving system.

\section{HUMAN COGNITIVE PERFORMANCE LIMITATIONS}

A large number of studies (Sage, 1981, 1984) show that, in an unaided condition, humans are very inadequate at a number of human information processing tasks. As a consequence of this, the associated acts of judgement and choice are often quite flawed. Simply supplying more of the vast amount of information, that is now potentially available, is not the answer as studies show that the presence of greater amounts of unstructured information may simply make the human problem solver's performance more erratic, due to the use of various forms of selective perception to cope with the vastly increased amount of information and associated cognitive overload. In the face of all of this, the human problem solver is likely to resort to time honored and tested methods of judgment that are based on wholistic and intuitive behavior. When true expertise is involved, these wholistic and intuitive approaches will often be both the appropriate response, and the effective and efficient one as well. There are many types of appropriate skill based behavior. There is much interest at this time in the design of artificial intelligence based systems that capture the skill based behavior of experts (Barr, Cohen and Feigenbaum, 1981 and 1982; Ben-Bassat and Freedy, 1982; Stefik and coworkers, 1982). There is also considerable interest in building decision support systems that assist humans in extrapolating from known and familiar situations using wholistic, skill-based approaches, such as reasoning by analogy (Carbonnel, 1983; Silverman, 1983).

When the environment, or contingency task structure as a more general descriptor, has changed and this change is not recognized; then it is very possible that the former 'master' becomes no master at all, except perhaps of the art of self deception. In situations such as this, when the 'expert' misjudges the degree of familiarity with the environment, the task, or the task requirements, then the 'expert' is not really an expert at all. The adoption of an intuitive skill based mode of behavior, when a formal analytical mode is called for, encourages various forms of selective perception, such as failure to seek potentially disconfirming information.

All of this has major implications with respect to the design of systems for the human user and requires, for appropriate system design, an understanding of human performance in problem solving and decision making tasks. This understanding has to be at a descriptive level, such that we can predict what humans will likely do in particular situations, and at a prescriptive level, such that we can aid humans in various cognitive tasks.

There are many situations in which this need for knowledge based support for the human operator is strong. With respect to man-machine systems, a prototypical task might concern automated systems that require: only occasional minor changes in parameter settings for maintenance of satisfactory performance; and rare major changes in the control inputs of a structural nature in order to prevent significant malfunction, and perhaps disaster. The need for significant interaction with an operational system will often be very infrequent. The advance notice of the need to interact will often be very short, the importance of the consequence of the human-machine interaction will be very large, the need to interact will occur at times that are very unpredictable, and there will be large amounts of information available when the potential need for operator interaction occurs. A specific description of the situation in which a knowledge based system is needed will form one of the bases for the determination of information and task requirements for knowledge base system design. The importance of appropriate knowledge representation to assist the human operator, and the need for suitable man-machine interaction and dialog is apparent. A number of other generic man-machine situations could be cited, that range from strategic planning to manual control of machine tools, and the need for decision support and associated knowledge representation would be easily recognized in each of them. Unfortunately, the activities that need to take place in order to establish the most appropriate knowledge representation and decision support system are not so transparent. 
For this reason, it is very important that the designer of man-machine systems be aware of various forms of knowledge representation (Abelson, 1979; Anderson, 1983; Axelrod, 1976; Carbonell, 1981; Card, Moran and Newell, 1983; Hayes-Roth, 1977; Sage and Lagomasino, 1983; Shneiderman, 1980) that are of value to these ends. The form, or frame, of knowledge representation that a person uses is very much a function of the perspective that the person has with respect to the particular issue under consideration. This suggests a contingency task structural approach as being very important. For it is the particular task at hand, the environment into which this task is imbedded, and the experiential familiarity of the human problem solver with the task and environment that determines the information acquisition and analysis strategy that is adopted as a precursor to judgment and choice. It is also very important to be aware of these concerns as they affect group and organizational behavior (Huber, 1982, 1983a, b; Sage, 1984). The success of the human in man-machine tasks is very much a function of how the human decides how to decide (Newell and Simon, 1972; Simon, 1978, 1983). Thus we need to be aware of a variety of knowledge representations; and the way in which meta-level knowledge leads to a knowledge representation in terms of the information rquirements determined for a particular task, the method of analyzing the acquired information, and the way in which associated facts and values are aggregated to enable judgment formation.

We have been especially concerned here with the fact that the information that is used for judgment and choice is typically not precise clerical and accounting data, but a mixture of this data and information of an imprecise and uncertain nature. As a consequence of this, there is a need for the consideration of approaches that allow incorporation of notions of imprecision (Gupta and Sanchez, 1982a, b; Rasmussen and Rouse, 1981; Sage and White, 1984; Schefe, 1980; Zadeh, 1973, 1975). We believe that it is an important area for continued research, together with the many other activities that are associated with understanding and improving the large variety of problem solving tasks associated with human cognitive activities that lead to the effective control of systems.

\section{HISTORICAL BACKGROUND, PRESENT NEEDS AND FUTURE PROSPECTS}

The first existence of concern relative to man-machine systems can be traced to the early days of simple machines powered by humans. With respect to human-system interfaces, these were designed intuitively. Thus the early designers of man-machine systems relied on their skill based experience for insurance of efficiency and effectiveness of the resulting system. Even today this is a very common method, as well it should be. With more complex and faster responding technological systems that operate in unfamiliar environments, however, it becomes more appropriate areas to consciously apply formal analytical methodologies and systematic techniques for the design of the man-machine system. Ultimate performance is achieved when man-machine system interfaces are designed, with an appropriate blend of skill based and formal knowledge based approaches, such that they support human activities in problem solving and control that vary across and are adaptive to human needs and limitations.

During the last 40 years, methodological knowledge has been gathered and systematic techniques have been elaborated. Most of the early investigations of man-machine systems were concerned with physiology based manual control tasks, often applied to aircraft piloting, later also to ship steering, car driving, and industrial process control. This work was accomplished by experimental psychologists, or by systems engineers, or by application-oriented engineers. Overviews of this research and literature surveys have been presented by Kelley (1968), Oppelt and Vossius (1970), Edwards and Lees (1974), Sheridan and Ferrell (1974), Johannsen and co-workers (1977), and McRuer (1980). Many control theoretic models have been developed to describe the behavior of the human operator in manual control tasks. The most sophisticated and well validated model seems to be the optimal control model first described by Kleinman, Baron, and Levison (1970). Models have been successfully applied as design tools for automatic control systems which improve the adaptation of the system to the human operator in a number of areas such as unburdening displays (Johannsen and Govindaraj, 1980; Rouse, 1977) as well as a number of other applications (Baron, 1980, 1982; Greenstein and Rouse, 1982; Rouse, Rouse and Hammer, 1982). Important research and development needs presently exist concerning the application of these models for the evaluation of combined realistic visual and motion cues, and for the evaluation of handling qualities in manual and partially automatic vehicle control.

With slower responding systems like ships and industrial process plants, it has become obvious that it is very difficult to explain human operator behavior by well established control theoretic methods. Human control behavior is highly nonlinear and intermittent in these cases. Intrinsic monitoring, decision making, and supervisory control behavior has become evident and this has attracted the attention of several investigators (Sheridan and Johannsen, 1976). 
Methodologies from systems science and operations research, such as network analysis, queueing theory, decision theory, fuzzy systems theory, information theory and many other approaches have been adopted and applied to man-machine systems research. Comprehensive extensions of the optimal control model have been developed using these approaches to enable description of broader human operator tasks, as well as the whole design process for complex man-machine systems. Accomplishments have been made with respect to discrete event simulation of humans in various tasks (Pritsker and Pegden, 1979), systems engineering models of human interactions with physical systems and processes (Baron, 1980, 1982; Moraal and Kraiss, 1981; Rouse, 1980) and with computers and the special requirements associated with computer interfaces (Card, Moran and Newell, 1983; Moran, 1981; Shneiderman, 1980; Sommerville, 1982). Further research along these lines is needed to combine different methods more successfully for purposes of modelling realistic mixtures of human tasks, machine tasks, and computerized decision support system (or expert system or knowledge based system) tasks.

The fuzziness and imprecision inherent in many task situations, and of human behavior in general, has to be taken into account more carefully as well. This has been recognized and, as a consequence, another root for the field of man-machine systems has come from cognitive science, or cognitive psychology, and computer science. These areas initially developed without any strong relationship or concern for human system interaction. Contemporary research in these areas concerns models of the brain, theories for memory and thought, as well as models for human and artificial intelligence, and problem solving (Earnst and Banerji, 1983; Klix, 1979; Newell and Simon, 1972). Several task analyses show that problem solving cognitive tasks are more important and critical to success of a given mission than physiologically control tasks for many man-machine systems. Therefore, cognitive sciences approaches have recently been applied for the analysis and design of these systems. Experimental investigations to these ends and, particularly, modelling of cognitive problem solving tasks, such as fault managing and planning as well as its interacton with controlling, needs much more research in the future.

Cognitive human operator workload has been investigated for many years (Moray, 1979). Although appropriate definitions and a common understanding concerning the importance of this research area exist, the reliability and validity of most workload measures is rather poor. Breakthrough in developments of new experimental techniques, as well as with respect to validated analytical models for workload that are applicable to a variety of human cognitive and physiological task categories is very much needed at this time.

Technological advances involving computers and electronic displays have changed, and will continue to change, man-machine systems for almost all application areas. This is true for industrial plants used for production or power generation, as well as for vehicles and transportation systems, and for aids to cognitive activities in planning, design, or operational activities. Due to the latter efforts at human support, office systems and information systems for observation, planning, executive support, management, and command and control tasks in business, defense, and medicine are similarly influenced by efforts in man-machine systems. These involve not only the operation of technological and management oriented information systems by highly skilled and knowledgable personnel, but also system use by the less skilled such as in mass transport. A major use for new generation man-machine systems is to provide computer assistance for the maintenance and for the design of technological systems.

A problem common to all these applications is the design of appropriate human-computer interaction subsystems. The possibly adaptive task allocation between human and computer, the dialog design including the use of natural language, and other software ergonomic aspects are especially important contemporary topics of research and development. The design of expert systems will lead to helpful tools in such areas as computer-aided decision making, information retrieval, and fault diagnosis.

With more computerization and higher degrees of automation, much greater attention must be paid to system design for human interaction. Contemporary advanced technologies potentially allow a more flexible work organization with higher user acceptance and job satisfaction. However, this potential advantage can only be achieved if the behavioral implications are seriously considered by the designers of computerized man-machine systems. Paradoxically, more sophisticated automation systems require greater human knowledge and more sophisticated human skills. These are needed such that it becomes possible for humans, at least in a supervisory capacity, to compensate for inevitable physical system limitations that are due to faults and changes in the environment.

Formalized procedures, now made possible through advances in computer and information sciences can be used to assist towards these ends. Introduction of human support systems made possible through these advances may tend to deteriorate user acceptance, job satisfaction, and job performance unless much attention is paid to 
human-system interaction concerns (Rijnsdore, Pikaar and Lenior, 1983; Vamos, 1983). The potentialities of computerization can only be realized if person-oriented criteria are introduced through sound application of systems engineering early in the design process. Here constructive cooperation between the behavioral and the technical aspects of systems design is essential to encourage cooperative systems based on not necessarily cooperative people.

\section{CONCLUSIONS}

We have examined contemporary research frontiers at the interface of areas of man-machine systems, human factors, artificial intelligence, decision support systems, and cognitive science. We have briefly discussed human-system interaction concerns that involve models of human problem solving behavior, models of human behavior in control tasks, displays including visual and auditory presentation, human work-load, and human proficiency and problem solving variations with experience and task demands. The implications of all of this for system design are very significant. They are currently being addressed through high level government committees (Pew, 1983) and contemporary research. Representative samples from this contemporary research are presented in the special issue in which this paper appears.

\section{REFERENCES}

Abelson, R. and M. J. Rosenberg (1958). Symbolic psycho-logic: a model of attitudinal cognition. Behavioral Sci., 3, 1 .

Abelson, R. (1979). Differences between belief and knowledge systems. Cognitive Sci., 3, 355.

Abelson. R. (1973). The structure of belief systems. In K. C. Schank and K. M. Colby (Eds), Computer Models of Thought. Freeman, pp. 287-339.

Anderson, J. R. (1983). The Architecture of Cognition. Harvard University Press.

Axelrod, R. M. (1972). Framework for a General Theory of Cognition and Choice. Institute of International Studies, University of California at Berkeley.

Axelrod, R. M. (Ed.) (1976). Structure of Decision: The Cognitive Mups of Political Elites. Princeton University Press.

Badre, A. (1982). Selecting and representing information structures for visual presentation. IEEE Trans Syst., Man \& Cybern. SMC-12, 495

Bailey, J. (1983). Job Design and Work Organization. PrenticeHall.

Baron, S. (1982). A framework for modeling supervisory control behavior of operators of nuclear power plants. Proceedings of the Workshop on Cognitive Modeling of Nuclear Plant Control Room Operators, Oak Ridge National Laboratory, pp. 36-52.

Baron, S. (1980). PROCRU: A Model for Analysing Crew Procedures in Approach to Landing. CR-152397, NASA Ames Research Center, Moffett Field, CA.

Barr, A., P. R. Cohen and E. A. Feigenbaum (Eds) (1981 and 1982). Handbook of Artificial Intelligence, Vols. I, II, and III. William Kaufman.

Ben-Bassat, M. and A. Freedy (1982). Knowledge requirements and management in expert decision support systems for (military) situation assessment. IEEE Trans Syst., Man \& Cybern., SMC-12, 479.

Bennett, J. L. (1983). Building Decision Support Systems. AddisonWesley.
Bobrow, D. G. and A. Collins (Eds) (1975). Represematrm ami Understanding: Studies in Cognitite Science. Academic Press. New York.

Burns, J. and R. P. Minch (1983). Conceptual design of decision support systems utilizing management science models. IEEF Trans Syst., Man \& Cybern., SMC-13.

Carbonell, J. G. (1981). Subjectite Understanding: Computer Models of Belief Systems. UMI Research Press, Ann Arbor, MI.

Carbonnel, J. G. (1983). Learning by analogy: formulating and generalizing plans from past experience. In R. SL Michalski and co-workers (Eds), Machine Lurning: An Artificial Intelligence Approach. Tioga, pp. 137.162.

Card, S. K., T. P. Moran and A. Newell (1983). The Prichology of Human-Computer Interaction. Lawrence Erlbaum.

Davis, R. (1979). Interactive transter of expertise: acquisition of new inference rules. Artificial Intelligence, 12, 121.

Dreyfus, S. E. (1982). Formal models vs human situational understanding: inherent limitations in the modeling of business expertise. Office: Technology and People, 1, 133.

Dreyfus, S. E. and H. L. Dreyfus (1980). A five stage model of the mental activities involved in directed skill acquisition. University of California at Berkeley, report ORC 80-2.

Duda, R. and E. Shortliffe (1983). Expert systems research. Science, 220, 261.

Earnst, G. W. and R. B. Banerji (1983). On the relationship between strong and weak problem solvers. Al Magazine, 4, 25.

Edwards, E. and F. P. Lees (Eds) (1974). The Human Operator in Process Control. Taylor and Francis, London.

Fick, G. and R. H. Sprague, Jr (1980). Decision Support Sistems. Issues and Challenges. Pergamon Press, Oxford.

Freedy, A. and E. Johnson (1982). Human factor issues in computer management of information for decisionmaking. IEEE Trans Syst., Man \& Cybern., SMC-12, 437.

Geiselman, R, and M. Samet (1980). Personalized versus fixed formats for computer-displayed intelligence messages. IEEE 7rans Syst., Man \& Cybern., SMC-12,490.

Greenstein, J. S. and W. B. Rouse (1982). A model of human decisionmaking in multiple process monitoring situations. IEEE Trans Syst., Man \& C ybern., SMC-12, 182.

Gupta, M. M. and M. Sanchez (Eds) (1982a). Approximate Reasoning in Decision Analysis. North-Holland.

Gupta, M. M. and M. Sanchez (Eds) (1982b). Fuzzy Information and Decision Processes. North-Holland.

Hayes-Roth, B. (1977). Evolution of cognitive structures and processes. Psychol. Ret., 34, 260.

Huber, G. P. (1982). Organizational information systems: determinants of their performance and behavior. Management Sci., 28, 138 .

Huber, G. P. (1983a). Issues in the design of group decision support systems. Management $S c i$. (in press).

Huber, G. P. (1983b). The nature and design of post-industrial organizations. Management $S c i$. (in press).

Johannsen, G., H. E. Boller, E. Donges and W. Stein (1977). Der Mensch im Regelkreis--Lineare Modelle. Oldenbourg, Munchen.

Johannsen, G. and W. B. Rouse (1979). Mathematical concepts for modeling human behavior in complex manmachine systems. Human Factors, 21, 733.

Johannsen, G. and T. Govindaraj (1980). Optimal control model predictions of systems performance and attention allocation and their experimental validation in a display design study. IEEE Trans Syst., Man \& Cybern., SMC-10, 249.

Johannsen, G. (1981). Human-computer interaction in decentralized control and fault management of dynamic systems. Proceedings of the IFAC 8th Triennial World Congress, Kyoto. Japan.

Johannsen, G. and W. B. Rouse (1983). Studies of planning behavior of aircraft pilots in normal, abnormal, and emergency situations. IEEE Trans Syst., Man \& Cybern., SMC-13.

Kantowitz, B. H. and R. D. Sorkin (1983). Human Factors: Understanding People System Relationships. John Wiley.

Keen, P. G. W. (1981). Information systems and organizational change. Commun. Assoc. Computing Machinery, 24, 24

Keen, P. G. W. and M. S. S. Morton (1978). Decision Support Systems: An Organizational Perspective. Addison-Wesley.

Kelley, C. R. (1968). Manual and Automatic Control. John Wiley. New York. 
Kleinman, D. L., S. Baron and W. H. Levison (1970). An optimal control model of human response - I. Theory and validation. Automatica, 6, 357.

Klix, F. (Ed.) (1979). Human and Artificial Intelligence. NorthHolland, Amsterdam.

McRuer, D. (1980). Human dynamics in man-machine systems. Automatica, 16, 237.

Miller, G. A. (1956). The magical number seven, plus or minus two: some limits on our capacity for processing information. Psychol. Rev., 63, 81.

Moraal, J. and K. F. Kraiss (Eds) (1981). Manned Systems Design-Methods, Equipment, and Applications. Plenum Press.

Moran, T. P. (Ed.) (1981). Special Issue on The Psychology of the Computer User. ACM Computing Surveys, 13.

Moray, N. (Ed.) (1979). Mental Workload: Its Theory and Measurement. Plenum Press.

Mumford, E. and D. Henshall (1979). A Participative Approach to Computer Systems Design. Associated Business Press.

Newell, A. and H. A. Simon (1972). Human Problem Solving. Prentice-Hall.

Nilsson, N. J. (1980). Principles of Artificial Intelligence. Tioga.

Norman, D. A. (1981). Perspectives on Cognitive Sciences. Lawrence Erlbaum.

Oppelt, W. and G. Vosslius (Eds) (1970). Der Mensch als Regler. VEB, Berlin

Pew, R. W. (Ed.) (1983). Research Needs for Human Factors. National Academy Press.

Pritsker, A. A. B. and C. D. Pegden (1979). Introduction to Simulation and SLAM. John Wiley, New York.

Rasmussen, J. (1983). Skills, rules, and knowledge: signals, signs, and symbols; and other distinctions in human performance models. IEEE Trans Syst., Man \& Cyber., SMC-13, 257.

Rijnsdorp, J. E., R. N. Pikaar and T. M. J. Lenior (1983). Proceedings Conference on New Technology and Ergonomics, Valenciennes.

Rasmussen, J. and W. B. Rouse (Eds) (1981). Human Detection and Diagnosis of System Failures. Plenum Press.

Rouse, W. B. (1977). Applications of control theory in human factors. Human Factors, 19.

Rouse, W. B. (1980). Systems Engineering Models of Human-Machine Interaction. Elsevier-North Holland, New York.

Rouse, W. B. (1982). A model of human decisionmaking in fault diagnosis tasks that include feedback and redundancy. $I E E E$ Trans Syst., Man, \& Cybern., SMC-9, 237.

Rouse, W.B. (1983). Models of human problem solving; detection, diagnosis, 'and compensation for system failures. Automatica, 19, 613.

Rouse, W. E. and S. H. Rouse (1983). Analysis and classification of human error. IEEE Trans Syst., Man, \& Cybern., SMC-13.

Rouse, S. H., W. B. Rouse and J. M. Hammer (1982). Design and evaluation of an onboard computer based information system for aircraft. IEEE Trans Syst., Man, \& Cybern., SMC-12, 451

Rouse, W. B., S. H. Rouse and S. J. Pelligrino. A rule based model of human problem solving performance in fault diagnosis tasks. IEEE Trans Syst., Man, \& Cybern., SMC-10, 366.

Sage, A. P. (1977). Methodology for Large Scale Systems. McGrawHill.

Sage, A. P. (1981). Behavioral and organizational considerations in the design of information systems and processes for planning and decision support. IEEE Trans Syst., Man, \& Cybern., SMC11. 640 .
Sage, A. P. (1983). Behavioral and organizational models for human decisionmaking. Policy Analysis and Information Science, Vol. 7, No. 2, Dec.

Sage, A. P. and C. C. White (1984). ARIADNE: A knowledge based interactive system for decision support. IEEE Trans Syst., Man, \& Cybern., SMC-14.

Sage, A. P. (1982). Methodological considerations in the design of large scale systems engineering processes. In Y. Haimes (Ed.), Large Scale Systems. North Holland, pp. 99-141.

Sage, A. P. and A. Lagomasino (1983). Knowledge representation and man-machine dialogue. In W. B. Rouse (Ed.), Advances in Man-Machine Systems Research. JAI Press.

Sage, A. P., B. Galing and A. Lagomasino (1983). Methodologies for the determination of decision support system information requirements. Large Scale Systems, 5.

Schefe, P. (1980). On foundations of reasoning with uncertain facts and vague concepts. Int. J. Man Machine Studies, 12, 35.

Schilling, D. A., A. McGarity and C. Revelle (1982). Hidden information and the display of information in multiobjective analysis. Management Sci., 28, 236.

Schneider, W. and R. Shiffrin (1977). Controlled and automatic human information processing: I. Detection, search, and attention. Psychol. Rev., 84, 1.

Sheridan, T. B. and W. R. Ferrell (1974). Man-Machine Systems: Information, Control, and Decision Models of Human Performance. MIT Press, Cambridge, MA

Sheridan, T. B. and G. Johannsen (Eds) (1976). Monitoring Behavior and Supervisory Control. Plenum Press, New York.

Shiffrin, R. M. and W. Schneider (1977). Controlled and automatic human information processing: II. Perceptual learning, automatic attending, and a general theory. Psychol Rev., 84, 127.

Shneiderman, B. (1980). Software Psychology: Human Factors in Computer and Information Systems. Winthrop.

Silverman, B. G. (1983). Analogy in systems management: a theoretical inquiry. IEEE Trans Syst., Man, \& Cybern., SMC13

Simon, H. A. (1978). On how to decide what to do. Bell $J$. Economics, 10, 974.

Simon, H. A. (1983). Reason in Human Affairs. Stanford University Press.

Sommerville, I. (1982). Software Engineering. Addison-Wesley. Sprague, Jr, R. H. and E. D. Carlson (1982). Building Effective Decision Support Systems. Prentice-Hall.

Stefik, M. and co-workers (1982). The organization of expert systems-a tutorial. Artificial Intelligence, 18, 135.

Ungson, G. R. and D. N. Braunstein (Eds) (1982) Decisionmaking: An Interdisciplinary Inquiry. Kent.

Vamos, T. (1983). Cooperative systems based on noncooperative people. Control Systems Magazine, 3(3), 9.

Winston, P. H. (1977). Artificial Intelligence. Addison-Wesley.

Wohl, J. G. (1981). Force management requirements for air force tactical command and control. IEEE Trans Syst., Man, \& Cybern., SMC-11, 618.

Zadeh, L. A. (1975). Fuzzy logic and approximate reasoning. Synthese, 30, 407.

Zadeh, L. A. (1973). Outline of a new approach to the analysis of complex systems and decision processes. IEEE Trans Syst., Man, \& Cybern., SMC-3, 28.

Zadeh, L. A. (1975). The concept of a linguistic variable and its application to approximate reasoning. Inform. Sci., 8, 199; $301 ; 9,43$. 